\title{
Open Posteromedial Dislocation of the Tibiotalar Joint without Associated Malleolar Fracture: A Case Report
}

\author{
Malick Diallo1, Patrick Wendpouire Hamed Dakoure1, Massadiami Soulama1, \\ Souleymane Ouedraogo', Salifou Gandema ${ }^{2}$ \\ ${ }^{1}$ Service d'Orthopedie traumatologie, CHU Souro Sanou de Bobo-Dioulasso, Bobo-Dioulasso, Burkina Faso \\ ${ }^{2}$ Service de Reeducation fonctionnelle, CHU Souro Sanou de Bobo-Dioulasso, Bobo-Dioulasso, Burkina Faso \\ Email:malikijallo@yahoo.com
}

How to cite this paper: Diallo, M., Dakoure, P.W.H., Soulama, M., Ouedraogo, S. and Gandema, S. (2016) Open Posteromedial Dislocation of the Tibiotalar Joint without Associated Malleolar Fracture: A Case Report. Open Journal of Orthopedics, 6, 331-336.

http://dx.doi.org/10.4236/ojo.2016.611044

Received: August 5, 2016

Accepted: November 13, 2016

Published: November 16, 2016

Copyright $\odot 2016$ by authors and Scientific Research Publishing Inc. This work is licensed under the Creative Commons Attribution International License (CC BY 4.0). http://creativecommons.org/licenses/by/4.0/

\section{(c) (i) Open Access}

\begin{abstract}
Background: Open pure tibiotalar dislocations with an associated superficial fibular nerve injury are rarely reported. Case presentation: The authors report a case of open tibiotalar dislocation without any associated fracture and an associated injury of superficial fibular nerve after a motorcycle accident. A debridement plus an open reduction and casting were performed sixteen hours after the trauma. After twenty-six months, the outcome was good without any infection and a sensitivity recovery of the foot. Conclusion: A delayed management of an open tibiotalar dislocation with an associated superficial fibular nerve injury led to a good mid-term outcome.
\end{abstract}

\section{Keywords}

Ankle, Tibiotalar Joint, Dislocation, Adult

\section{Introduction}

An isolated tibiotalar dislocation (TTD) without associated fracture is a rare occurrence [1]-[6]. Since Peraire in 1913 [4], we found 185 sporadic cases in literature. More than fifty percent of them are posteromedial dislocations [2] [3] [6]. Anterior TTD [2], superior or vertical TTD with a proximal displacement of the talus between tibial et fibular malleolus [2] and rotatory TTD [7] was rarer. Open dislocations were common with various anterolateral skin lacerations [2] [3] [6]. Other associated complications such as vascular injuries [3] [5], nervous injuries [2] [5] and extensor tendons disruptions [2] were rarely reported. We report the case of a 35-years-old driver who presented an open posteromedial TTD with an associated superficial fibular nerve (SFN) injury with 
a good outcome and after 26 months.

\section{Case Report}

A 35 years-old driver sustained an open right ankle injury after a motorcycle accident. The motorcycle on which he was riding at over $100 \mathrm{~km}$ per hour stopped suddenly and he fell on his right side. It was a sudden mechanical issue and the motorcycle felt over his right foot. His right ankle seemed to be forced in plantar flexion and eversion. He arrived at our Emergency Department (ED) fourteen hours after the trauma. The trauma occurred in a rural land at $200 \mathrm{~km}$ from our hospital. The wound was irrigated with water and saline solution in two rural hospitals. On admission, the right foot was severely deformed and laid medially. It was a large ankle anterolateral wound with exposed anterolateral distal tibia and lateral malleolus covered by mud. No motion was possible at the ankle. Posterior tibial and dorsal pedal pulses were palpable. It was an anesthesia on the intermediate dorsal cutaneous nerve territory at the dorsal surface of the foot and toes were mobile.

The ankle anteroposterior and lateral radiographs revealed complete posteromedial displacement of the foot and telluric debris without any associated fracture (Figure 1(a) \& Figure 1(b)).

Under general anesthesia, a surgical exploration was undertaken sixteen hours after trauma. There was no injured artery and tendinous structures but a superficial fibular nerve (SFN) disruption. Capsule-ligamentous attachments of the ankle with exception of distal tibiofibular ligaments were completely disrupted.

The wound was irrigated and debrided with saline solution and the joint was reduced by simple axial traction on the heel and lateral translation. The articular capsule was not sutured. Mid substance disruptions of ligamentous structures (the deltoid ligament, the anterior tibiofibular ligament and the calcaneofibular ligament) were found suturable and repaired. The SPN was no repaired, the proximal stump was buried. The wound was primarily closed without drain. The range of motion under sedation was full with instability in inversion. A windowed below knee cast was applied with the ankle in

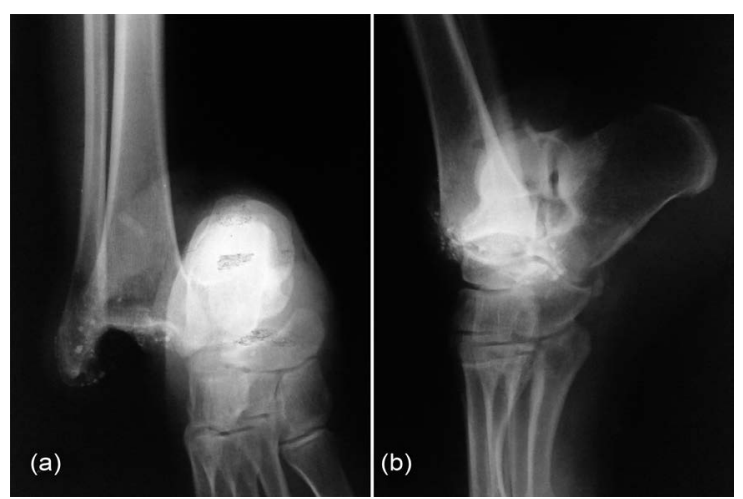

Figure 1. Radiographs of the right ankle. (a): Anteroposterior (AP) view: medial displacement of the whole foot, bony superposition between the medial malleolus and calcaneus and telluric debris around tibial and fibular malleoli. (b): Lateral view: bony superposition between tibia, fibula and talus and telluric debris around tibial and fibular malleoli. 
neutral position for six weeks. Immediate postoperative radiographs showed an anatomic reduction (Figure 2(a) \& Figure 2(b)). The patient received four weeks antibiotics with amoxicillin/clavulanate.

The wound healed in twelve weeks. No infection occurred and a partial weightbearing was authorized six weeks after surgery. Twelve weeks postoperative rehabilitation was performed. The patient returned to work after twelve weeks as car-driver. Superficial cutaneous sensitivity (pain, temperature and light touch) of the intermediate dorsal cutaneous nerve territory recovered after twelve months. Twenty-six months after surgery, it was no limitation in activities, a normal gait but he complained sporadic pain in cold time and in long walking distance $(1 \mathrm{~km})$ and sporadic paresthesia in intermediate dorsal cutaneous nerve territory. Clinical examination found an anterolateral atrophic scar, a stable ankle (anteroposterior and varus-valgus plans) and mobility from $10^{\circ}$ for dorsal flexion to $30^{\circ}$ of plantar flexion (Figure 3 ). The outcome rating according to the American Orthopedic Foot and Ankle Society (AOFAS) was 87. Radiographs showed posterior calcifications, short medial malleolus with Elise ratio of 0.50 and slight tibiotalar arthritis (Figure 4(a) \& Figure 4(b)).

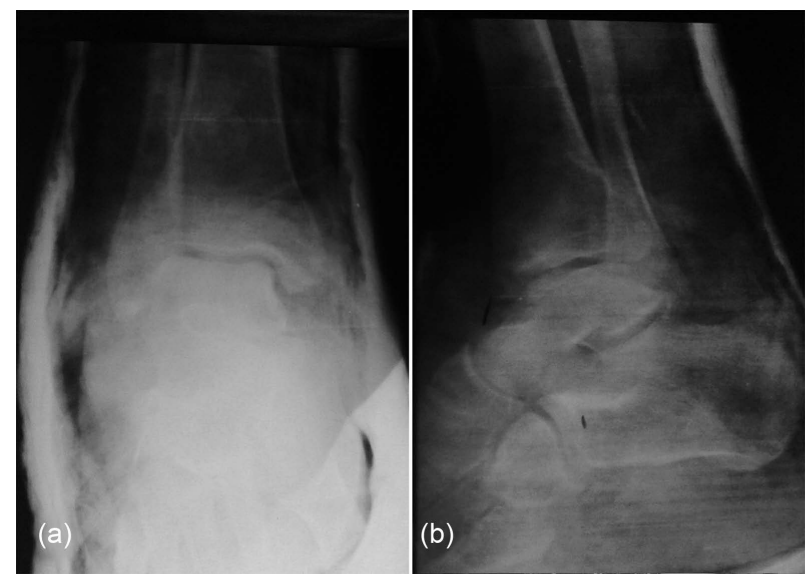

Figure 2. Immediate post-operative AP radiograph (a) and lateral radiograph (b) showed an anatomic reduction.

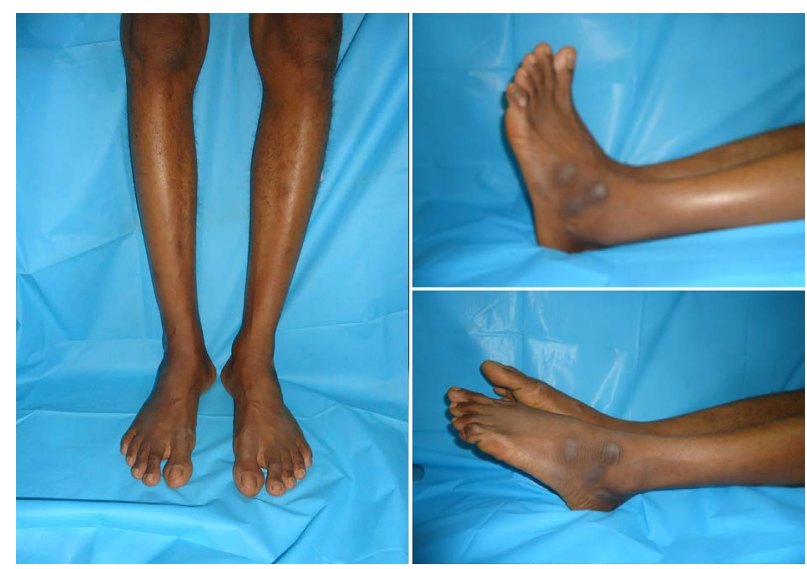

Figure 3. Range of mobility after twenty-six months. 


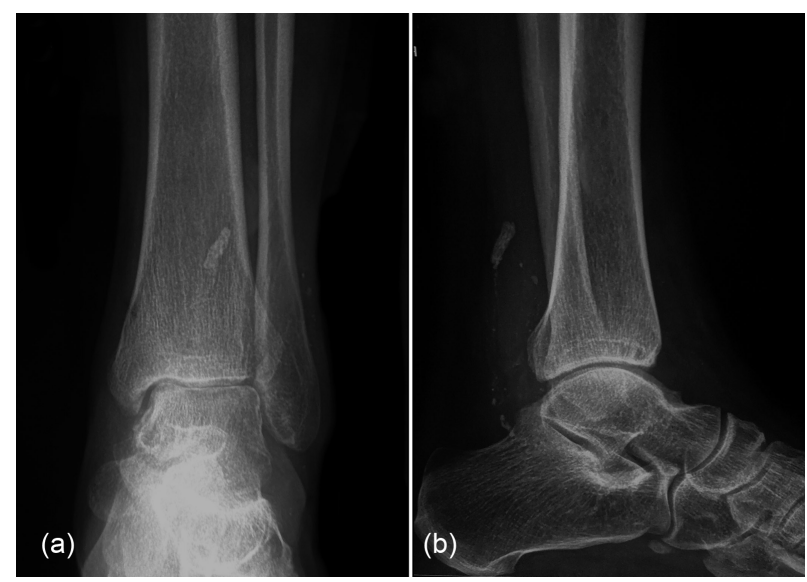

Figure 4. AP radiograph (a) and lateral radiograph (b) of the right ankle at twenty-six months. We noted posterior calcifications and degenerative changes at medial side of the tibiotalar joint.

\section{Discussion}

With exceptions as Elise and coworkers which collected 16 cases from two hospitals in 25 years [2], tibiotalar dislocations were usually reported as case reports [1] [4] [5] [6] [8].

\section{Mechanisms of Injury}

High-energy trauma such as motor vehicle accident and sports traumas are involved in open tibiotalar dislocations [5] [6] [9]. The rhomboidal shape of the talus makes it instable in plantar flexion [9] [10]. Our case was due to a high energy fall after a sudden motorcycle stop and fall on the ankle. Cadaveric experimentations showed that the tibiotalar joint can be dislocated posteromedially in plantar flexion and inversion [10]. The failure of capsulo-ligamentous structures allows the foot dislocation. Some conditions like hyperlaxity, medial malleolus hypoplasia, sprains and weakness of fibular muscles are predisposing factors of tibiotalar dislocations [2] [11]. Elise ratio was calculated by dividing the medial malleolus height and the fibular malleolus height. The normal ratio varies between 0.58 and 0.60 [2].

\section{Diagnose and Complications}

Usually, in isolated posteromedial tibiotalar dislocation, the ankle is severely deformed and the foot lied behind and inside the axis of the leg [3]. The wound usually is located on the opposite side of the foot displacement [3] [6]. SFN and his two branches, intermediate dorsal cutaneous nerve and medial dorsal cutaneous nerve, are located anterior to the lateral malleolus [12]. Nerves are exposed when the ankle move to plantar flexion [13]. So, sensitivity must be checked before and after surgery on SFN territory. We was not repaired the SPN because of loss of substance.

\section{Treatment and Outcome}

An open posteromedial tibiotalar dislocation is treated by open reduction after the wound debridement [2] [5] [6] [9] [11]. A thorough debridement is a keystone to avoid any infection. Delayed wounds are not commonly primarily closed. The wound of our 
patient allowed a primary closure after a thorough irrigation to remove all the mud. Bakshi [14] used temporary Kirschner wires to stabilize an unstable ankle after reduction. The cast duration was six [3] [15] to eight weeks [5] with weight-bearing authorized at four to six weeks [5]. The outcome of open dislocation is not as good as closed dislocation [2] [5]. Calcifications of the medial collateral ligament and the posterior capsule were found after two years and tibiotalar osteoarthritis was rare [2] [6]. The main reported complications were stiffness [9] [11] long-term dysesthesia [2] [11] and gangrene in associated vascular injuries [1] [2]. Associated ankle rehabilitation reduces stiffness rate. Associate osteochondral lesions lead to osteoarthritis [8].

\section{Conclusion}

The SFN and his branches are exposed in posteromedial dislocation. Our case presented a delayed management of an open dislocation with an associated SFN injury. The outcome after twenty-three month was good without any sign of infection and a partial spontaneous cutaneous neurologic recovery in SFN territory.

\section{Patient Consent}

The patient was informed that data concerning the case would be submitted for publication, and he provided consent.

\section{Disclosure}

The authors report no conflict of interest concerning the materials or methods used in this study or the findings specified in this paper.

\section{References}

[1] Wilson, M.J., Michele, A.A. and Jacobson, E.W. (1939) Ankle Dislocations without Fracture. The Journal of Bone \& Joint Surgery, 21, 198-204.

[2] Elise, S., Maynou, C., Mestdagh, H., Forgeois, P. and Labourdette, P. (1998) Les luxations tibio-astragaliennes pures. A propos de 16 observations. Acta Orthopaedica Belgica, 64, 25 34 .

[3] Colville, M.R., Colville, J.M. and Manoli, A. (1987) Posteromedial Dislocation of the Ankle without Fracture. The Journal of Bone \& Joint Surgery, 69, 706-711. http://dx.doi.org/10.2106/00004623-198769050-00011

[4] Péraire (1913) Luxation tibio-astragalienne avec issue a l'extérieur du péroné non fracturé à travers une boutonnière cutanée. Presentation de malade. Paris Chir V:959.

[5] Ngai, W.K., Chan, Y.F. and Lui, T.H. (2004) Pure Ankle Dislocation. Journal of Orthopaedic Surgery (Hong Kong), 8, 72-77.

[6] Lazarettos, I., Brilakis, E. and Efstathopoulos, N. (2013) Open Ankle Dislocation without Associated Malleolar Fracture. The Journal of Foot and Ankle Surgery, 52, 508-512. http://dx.doi.org/10.1053/j.jfas.2013.03.017

[7] Shaik, M.M., Tandon, T., Agrawal, Y., Jadhav, A. and Taylor, L.J. (2006) Medial and Lateral Rotatory Dislocations of the Ankle after Trivial Trauma-Pathomechanics and Management of Two Cases. The Journal of Foot and Ankle Surgery, 45, 346-350. http://dx.doi.org/10.1053/j.jfas.2006.05.002 
[8] Lui, T.H. and Chan, K.B. (2012) Posteromedial Ankle Dislocation without Malleolar Fracture: A Report of Six Cases. Injury, 43, 1953-1957.

http://dx.doi.org/10.1016/j.injury.2012.07.002

[9] Hatori, M., Kotajima, S., Smith, R.A. and Kokubun, S. (2006) Ankle Dislocation without Accompanying Malleolar Fracture. A Case Report. Upsala Journal of Medical Sciences, 111, 263-268. http://dx.doi.org/10.3109/2000-1967-055

[10] Fernandes, T. (1976) The Mechanism of Talo-Tibial Dislocation without Fracture. The Journal of Bone \& Joint Surgery, 58-A, 364-365.

[11] Rivera, F., Bertone, C., De Martino, M., Pietrobono, D. and Ghisellini, F. (2001) Pure Dislocation of the Ankle: Three Case Reports and Literature Review. Clinical Orthopaedics and Related Research, 382, 179-184. http://dx.doi.org/10.1097/00003086-200101000-00024

[12] Solomon, L.B., Ferris, L., Tedman, R. and Henneberg, M. (2001) Surgical Anatomy of the Sural and Superficial Fibular Nerves with an Emphasis on the Approach to the Lateral Malleolus. Journal of Anatomy, 199, 717-723. http://dx.doi.org/10.1046/j.1469-7580.2001.19960717.x

[13] de Leeuw, P.J., Golanó, P., Sierevelt, I. and van Dijk, C.N. (2010) The Course of the Superficial Peroneal Nerve in Relation to the Ankle Position: Anatomical Study with Ankle Arthroscopic Implications. Knee Surgery, Sports Traumatology, Arthroscopy, 18, 612-617. http://dx.doi.org/10.1007/s00167-010-1099-z

[14] Bakshi, K. (2016) Open Axial and True Vertical Ankle Dislocation without Malleolar Fractures: A Case Report. The Journal of Foot and Ankle Surgery, 55, 176-180. http://dx.doi.org/10.1053/j.jfas.2014.10.013

[15] a la Denise, J.P., Tabib, W. and Pauthier, F. (2009) Long-Term Result of a Pure Tibiotalar Dislocation in a Child. Orthopaedics \& Traumatology-Surgery \& Research, 95, 558-562. http://dx.doi.org/10.1016/j.otsr.2009.06.007 for you:

Accepting pre-submission inquiries through Email, Facebook, LinkedIn, Twitter, etc. A wide selection of journals (inclusive of 9 subjects, more than 200 journals)

Providing 24-hour high-quality service

User-friendly online submission system

Fair and swift peer-review system

Efficient typesetting and proofreading procedure

Display of the result of downloads and visits, as well as the number of cited articles

Maximum dissemination of your research work

Submit your manuscript at: http://papersubmission.scirp.org/

Or contact ojo@scirp.org 